\title{
Sujeto Político y ORden Social
}

\author{
Marcelo Carlos Altomare
}

RESUMEN: Este trabajo reconstruye tres modelos teóricos de articulación del nexo sujeto político-orden social, representados por Hobbes, Marx y Laclau. Hobbes afirma que el sujeto politico-el soberano- crea el orden socio-jurídico. Para Marx el sujeto político-la clase social- es producida por el orden socio-histórico. Laclau, por su parte, piensa que el sujeto politico -sujeto de la hegemonía- no es ni bacedor ni criatura del orden social, sino el proceso de constitución de una identidad colectiva y general conformada a partir de identidades parciales y particulares, que están desagregadas como resultado de la desintegración simbólica del orden social.

CONCEPTOS CLAVES: sujeto político, orden social, soberano, clase social, hegemonía

\section{I}

La crítica a las concepciones esencialistas de las identidades colectivas condujo al pensamiento social y político a repensar la teoría del sujeto. El estudio de las teorías del sujeto gestadas por distintas tradiciones teóricas modernas junto a la investigación de las condiciones de constitución de la subjetividad se transformaron, en consecuencia, en algunas de las temáticas más relevantes de la agenda de las ciencias sociales de fin de siècle (Giddens, 1994; Habermas, 1989; Touraine, 1994). Entre las dimensiones conceptuales del debate destaca notoriamente aquella que entiende al lenguaje como el lugar de constitución de la 
subjetividad. Al trasladarse esta cuestión referida a las identidades al campo de la política, los estudios de teoría social concentraron sus intereses en torno a la indagación de las relaciones entre sujeto, representaciones sociales y orden politico. En el marco de esta perspectiva analítica creemos que es plausible llevar a cabo una serie de indagaciones sobre la argumentación desarrollada por Hobbes, Marx y Laclau (Hobbes, 1991, 1985; Marx, 1974, 1977; Laclau \& Mouffe, 1987; Laclau, 1993), en cuanto allí se nos ofrecen tres maquetas teóricas basadas en la articulación de los ejes conceptuales mencionados.

El nudo del pensamiento de Hobbes es orientado por un tópico capital del pensamiento político al que interroga en los siguientes términos: cuáles son las condiciones de conformación y permanencia de un orden político estable si consideramos que el problema base de la política reside en el insuficiente poder monopolizado por la soberanía? $\mathrm{Su}$ pensamiento es una reflexión sobre las causas del origen y de la disolución del estado, su preocupación es responder a los problemas de un poder político que habitualmente no peca por exceso sino por defecto, por lo cual realiza una evaluación de los problemas de funcionamiento de las relaciones entre gobernantes y gobernandos desde la perspectiva de los derechos del soberano - ex parte principis -. Esta doble dimensión del problema lo conduce al estudio de las condiciones de posibilidad necesarias para la creación del orden político estable, a la indagación acerca las probabilidades de desplazamiento del conflicto. Traducido a lenguaje hobbesiano, el problema se encuentra en el pasaje de un estado de naturaleza, caracterizado como bellum omnium contra omnes, hacia otro donde impera una relación de reciprocidad entre súbdito y soberano sustentada en el axioma fundamental de la política: el nexo entre obediencia y protección. De modo que el desplazamiento de la guerra civil entre agrupamientos humanos se transforma en la conditio sine qua non de la generación de un orden político que garantice una paz interior. La investigación hobbesiana recaerá simultáneamente sobre las causas que 
provocan el funcionamiento de la lógica de la enemistad política y, a la vez, sobre sus modalidades de neutralización. En consecuencia el pensamiento de Hobbes bascula entre dos modelos de convivencia humana radicalmente heterogéneos: la guerra civil del estado de naturaleza y la paz interior del estado. El mutuo reenvió de los pares conceptuales guerra civil y paz interior, conflicto y neutralización, protección y obediencia, estado de naturaleza y estado político sólo se explica a través de una reductio ad bominem llevada a término por una formalización hobbesiana partícipe de la invención moderna que con Descartes hace del yo el bypokeimenon o fundamento último de todo lo existente. Es justamente el hombre la pieza nodal del modelo hobbesiano, esto es, la materia y el artífice del Commonvealth; de este modo el hombre deviene hacedor sustantivo del proceso de generación del orden político. Sobre el estudio de este hombre, pues, Hobbes fundará su análisis de la neutralización de la guerra en cuanto condición de constitución del sujeto político representado en el ejercicio de la soberanía.

En la divisoria establecida por la escritura del Leviathan entre "cuerpos naturales [Naturall Bodies]" y "cuerpos políticos [Politique Bodies]" -que corresponden a la separación entre "Naturall Philosophy" y "Civill Philosophy" respectivamente-, Hobbes indaga al hombre dentro de la primera de estas categorías. Más precisamente, el hombre es investigado en tanto cuerpo caracterizado por un tipo específico de "cualidades [Qualities]", que lo diferencia respecto de los restantes: las "pasiones [Passions]". Así el conocimiento de las "consecuencias de las pasiones de los hombres [Consequences from the Passions of Men]" constituye el fundamento metodológico para el estudio del espacio de lo político.

En principio el hombre se distingue dentro del mundo físico debido a que es un cuerpo regido mediante "mociones voluntarias [Voluntary motion]". Estas mociones voluntarias -v. g. andar, hablar, 
etc.- se diferencian de las "mociones vitales" porque suponen que fueron anticipadas por el hombre en su mente. A estas anticipaciones mentales Hobbes las analiza bajo el concepto de "fantasía [Fancy]", considerada como un resto de la "representación [Representation]", la que resulta de la impresión generada sobre el sujeto cuando alguna de las cualidades de un cierto "objeto [Object]" externo opera sobre determinadas "partes del cuerpo humano". La fantasía es, entonces, el retiro de la "sensación [Sense]", específicamente, aquel resto que permanece cuando "el objeto ha sido apartado de nosotros": el recuerdo. Alojada en el sitio de producción de los "pensamientos del hombre [Thougts of man]" -y finalizado el proceso sensitivo- se conforma la "imaginación [Imagination]", la "sensación decadente" que Hobbes separa respecto del "decaimiento [decay]" o "memoria [Memory]". De manera que el "origen interno [internall beginning]" de las pasiones -o mociones voluntarias- es un "pensamiento precedente [precedent thought]" al que se considera como "imaginación".

Inmediatamente antes del comienzo de cualquiera de las "acciones [actions]" emprendidas por el hombre, Hobbes ubica aquello que denomina "esfuerzo [Endeavour]"; este se denomina "deseo [Desire]" si "se dirige hacia algo que lo causa", o "aversión [Aversion]" si "se traduce como apartamiento de algo". Es en este sentido que respecto de cualquiera de los objetos deseados por el hombre "se dice también que lo aman"; mientras "que odian aquellas cosas por las cuales tienen aversión". Asimismo agrega que el deseo es acompañado por la "ausencia del objeto [Absence of the Object]", estando el amor, por el contrario, vinculado a la "presencia del objeto [Presence of the Object]". De igual manera sucede cuando consideramos, por un lado, a la aversión en tanto rechazo de un objeto ausente y, por el otro, al odio como "presencia del mismo".

El hombre es un cuerpo natural autónomo debido a que posee en sí mismo la capacidad de desarrollar un movimiento voluntario hacia -o 
apartándose de- un objeto externo, habiendo previamente imaginado en su mente tal acción en forma de un esfuerzo: ello es el núcleo de la pasión que -según Hobbes- rige la conducta humana. En efecto, lo real es concebido como una realidad física compuesta únicamente por cuerpos en movimiento, entre los cuales aparece el hombre qua cuerpo humano regido por movimientos voluntarios denominados pasiones.

$\mathrm{El}$ hombre del pensamiento político moderno, entonces, no "es por naturaleza un animal social", ni tampoco "miembro de la ciudad"; en oposición a tal definición, el hombre hobbesiano es un cuerpo en movimiento sujeto a sus pasiones y, al mismo tiempo, autónomo en referencia a cualquier orden político y social. En el campo del pensamiento político, la independencia ontológica del hombre respecto de la comunidad política condujo a considerar a ésta conforme al modelo de una asociación no natural -un cuerpo artificial. Consecuentemente la representación de la comunidad política cobró la forma de un "artefacto [Engines]" de relojería construido por el "arte del hombre", convirtiendo a éste en el "artífice [Artificer]" de aquella máquina (Habermas, 1966).

Sobre este punto el pensamiento político de Hobbes articula en una misma reflexión su indagación en torno al hombre y su conceptualización acerca del estado. A tal efecto, Hobbes recurre a la construcción de una ficción conceptual que le permite describir los lazos sociales establecidos entre los hombres a partir de un hipotético status naturalis o "Naturall Condition [condición natural]". Desarrolla alli, por un lado, una conceptualización de la "naturaleza humana [nature of man]", -parte integrante de su teoría de las pasiones-, $y$, por otro, un pensamiento sobre las condiciones de construcción de un "poder común [common Power]". $\mathrm{El}$ hombre aparece caracterizado no sólo como un cuerpo en movimiento sometido a sus pasiones, sino también en tanto poseedor de un saber -un arte- acerca del modo de construcción de la comunidad política: los hombres son, pues, los "hacedores [Makers]" del Common-Wealth. 
Parece lógico pensar que Hobbes produce por medio de un único giro conceptual dos cambios absolutamente significativos: en primer término, modela una teoría de la legitimidad en la que el hombre emerge a modo de fundamento del orden político, $y$, en segundo lugar, diseña un conocimiento sobre el espacio político en el que una indagación de las pasiones humanas será esencial para la conceptualización sobre el Estado.

Hobbes comprende la "acción [action]" del hombre a modo de un permanente "movimiento [motion]", subsumido a un insaciable deseo de "felicidad [Felicity]" que lo compele a una perpetua búsqueda de objetos que satisfagan su "apetito". Inmediatamente antes de esta acción se encuentra la "voluntad [Will]", o el "acto de querer [Act of Willing]" -i. e. el apetito que surge como producto de la "deliberación [Deliberation]". Es este último el proceso desencadenado completamente "en la mente del hombre [in the mind of man]" cuando el mismo se representa las "consecuencias [consequences] buenas y malas" derivadas de sus "actos u omisiones" y, simultáneamente, la correspondencia de ellas en relación a "los apetitos y aversiones, esperanzas [Hopes] y temores [Feares]" que despiertan "una y la misma cosa".

Lejos de conducirlo hacia un estado de reposo, el "éxito continuo" que posibilita al hombre obtener aquellas cosas deseadas -i. e. la felicidad- renueva el movimiento, colocándole en un estado de in-quietud a perpetuidad. Hobbes invierte aquí la valoración clásica del pensamiento antiguo que subordinaba la acción [praxis] a la contemplación [theoria], el movimiento al reposo, el cambio a la inmutabilidad, lo efímero a lo eterno. No habiendo absolutamente nada que ofrezca "tranquilidad a la mente [Tranquillity of Mind]", y siendo la "vida" un incesante movimiento, el hombre no puede estar exento de deseos, temores y sensaciones. 
En este sentido, la estructura del deseo que impulsa al hombre hobbesiano hacia la obtención del objeto de satisfacción lo conduce a un nuevo estado de no-satisfacción. El logro de un bien futuro como un progreso continuo de un objeto a otro forma el núcleo del componente motivacional que rige la acción del hombre: la vida se presenta, pues, como una "lucha por la felicidad [struggle for hapiness]". No hay objeto que satisfaga el deseo humano en la medida que toda satisfacción es sólo fugaz; por tanto ésta renueva el estado de in-satisfacción. La felicidad, entonces, es para el hombre un "continuo progreso de los deseos [continuall progresse of the desire], ya que la consecución del primero no es otra cosa sino un camino para realizar otro ulterior ... (a fin de) asegurar para siempre la vía del deseo futuro ... ( $\mathrm{y}$, en consecuencia,) una vida feliz [contented life]" (Hobbes, 1991).

$\mathrm{Al}$ estar ausente el objeto que posibilite la satisfacción completa del deseo humano, se niega de raíz toda configuración de un saber acerca de aquellos bienes que producen felicidad para el hombre: "la felicidad en esta vida no consiste en la serenidad de una mente satisfecha". La causa de este perpetuo movimiento del deseo humano debe buscarse en la inexistencia de un "finis ultimus (propósitos finales) o summum bonum (bien supremo) presente en los textos de los viejos filósofos (Hobbes, 1991)". Vaciado el lugar del saber sobre un supuesto objeto último de satisfacción, el hombre deviene -en el pensamiento hobbesiano- un cuerpo en permanente movimiento, arrojado hacia un estado de continua in- quietud a causa de un deseo que no cesa de no satisfacerse.

La in-quietud permanente del deseo humano supone la inexistencia de objetos de satisfacción últimos para cualquier hombre; es una "continua mutación [continuall mutation]" que somete sin cesar a la "constitución del cuerpo humano [constitution of a mans Body]", haciendo, incluso, imposible que las "mismas cosas causen siempre en la misma persona los mismos apetitos y aversiones". Siendo ésta la lógica 
que regula el deseo del sujeto será, entonces, poco probable que puedan "coincidir [consent] todos los hombres en el deseo de uno y el mismo objeto" (Hobbes, 1991).

Se deduce de ello la existencia de una multiplicidad de objetos que pueden satisfacer el deseo del hombre: la "similitud de las pasiones [similitude of Passions]"-postula Hobbes- está cruzada por la ausencia de "semejanza entre los objetos de las pasiones". Por esta razón, cualquier objeto apetecible para el deseo humano es valorado como "bueno [Good]" mientras será considerado "malo [Evill]" aquel otro que cause aversión. Las cualidades dependen de posiciones subjetivas por cuanto no son propiedades inmanentes a los objetos; únicamente adquieren sentido "en relación con la persona que las utiliza". No hay pues "ninguna regla de bien y de mal (que) pueda tomarse de la naturaleza de los objetos [nature of the objets]"; la existencia de "reglas comunes [common Rule]" sólo puede emerger de la decisión de un "árbitro [Arbitrator] o juez Judge]" instituido por "consenso [consent]", a los efectos de "imponer como sentencia su regla del bien y del mal": es este el problema y la solución al desorden del status naturalis.

Careciendo de significado cualquier tipo de postulado normativo y no habiendo un juez que arbitre sobre reglas de convivencia común, cuando dos hombres tienen una y la "misma cosa [same thing]" como objeto de deseo "devienen enemigos [become enemies]".

Hobbes abandona paralelamente toda concepción que represente a los hombres como desiguales -visión presente en el pensamiento clásico-, de manera tal que la "naturaleza [nature]" constituye hombres "tan iguales en las facultades del cuerpo y del espíritu" que ninguno puede reclamar "un beneficio cualquiera al que otro no pueda aspirar como él"; además siendo iguales en su capacidad, los hombres tienen la "igualdad de esperanza respecto a la consecución de sus fines". Consecuentemente los hombres se colocan en una condición de "guerra [Warre]" en razón de una convivencia humana llevada a cabo "sin un 
poder común [without a common Power]" que los coaccione. Se desprende, entonces, que Extra civitatem nulla salus para "la vida del hombre", siendo ésta "solitaria [solitary], pobre [poore], tosca [nasty], embrutecida [brutish] y breve [short]". Alli "donde todo hombre es enemigo [Enemy] de todo hombre" no existe una convivencia humana en la cual impere la "razón", ni la "paz", aún menos la "seguridad"; es el espacio y el tiempo de una convivencia humana que no puede ser otra cosa que "guerra civil [civill Warre]".

En esta condición natural -según Hobbes-, no hay deseos que puedan ser considerados "pecados [Sin]", ni acciones catalogadas como "injustas [Unjust]", tampoco existe "propiedad, ni dominio, ni distinción entre tuyo y mío". Esto sucede a causa de no haber "ley [Law]" alguna que prohiba el ejercicio de determinadas conductas, no pudiendo aquella ser sancionada mientras "los hombres (no) se pongan de acuerdo [agree] con respecto a la persona [Person] que debe promulgarla". Resultado de la falta de un "fin último" o "bien supremo", la multiplicidad de perspectivas valorativas que sustentan los hombres inhibe posibilidad de acuerdo sobre las reglas normativas indispensables para la conformación de un orden político pacífico.

La vía de salida de tal estado de guerra acontece mediante la conjunción de las "pasiones [Passions] que inclinan [encline] a los hombres a la paz [Peace]" y la "razón [Reason] (que) sugiere adecuadas normas [Articles] de paz", producto del "consenso [agreement]" entre los hombres -i. e. las leyes naturales. Entre las pasiones que inclinan a los hombres hacia la paz se encuentran, por un lado, el esfuerzo. por apartarse de los objetos cuya representación aparezca al sujeto asociada a la idea de muerte: "miedo a la muerte [Feare of Death]", por el otro, el esfuerzo hacia las cosas que en la representación subjetiva están ligadas a una vida confortable y son factibles de ser obtenidas a través de la industria. 
Pese al perspectivismo ético-normativo que impera sobre las pasiones y acciones de los hombres en el "estado de naturaleza [state of nature]", Hobbes halla un elemento de valor común a todos los individuos: el "derecho natural [Right of Nature]", la libertad que posee cada uno de los hombres para "preservar su propia naturaleza [preservation of his own Nature], su propia vida [own Life]". Todo hacer que el hombre, mediante el "juicio Judgement]" y la "razón [Reason]", considere necesario para su propia preservación forma parte de su libertad, entendida ésta como "ausencia de impedimentos externos [absence of externall Impediments]". Asimismo se encuentra la "ley natural [Naturall Law]" que funciona a modo de "precepto [Precept] o regla general [generall Rule]" de la razón, enunciado que "se le prohibe a un hombre hacer lo que pueda destruir su vida". Aun cuando Hobbes subraye la diferencia entre la libertad del derecho natural y la obligación de la ley natural, postula que la ley fundamental de la naturaleza contiene a ambas al prescribir que "cada hombre debe esforzarse por la paz [Peace] mientras tiene la esperanza de lograrla; y cuando no puede obtenerla, debe buscar y utilizar todas las ayudas y ventajas de la guerra [Warre]"(Hobbes, 1991).

De esta ley natural fundamental se deduce la posibilidad de que cada uno de los hombres tiene de renuncie a su "derecho a todas las cosas" en la medida que todos lleven a cabo igual renunciamiento. A partir de esta acción comienzan a establecerse nuevos tipos de "lazos [Bounds] por medio de los cuales los hombres se sujetan y obligan ... (a causa del) temor [Feare] (que se desprende) de alguna mala consecuencia resultante de la ruptura [rupture]" del pacto de renunciamiento. Esto es el "contrato [Contract]" entendido a modo de una "mutua traslación o cambio de derechos", derivado de signos expresos como la palabra. No obstante, será necesario la presencia de alguien que garantice dicha palabra, de lo contrario la promesa estará debilitada en relación a su cumplimiento: así los "pactos [Covenants] -nos dice Hobbes- que no 
descansan en la espada [Sword] no son mas que palabras [Words], sin fuerza para proteger al hombre". Es en el proceso de constitución del lugar de una garantía para el cumplimiento de la promesa ofrecida en la palabra donde hallamos la decisión de un hombre que aparece como yo autónomo: lo político encuentra su fundamento en el "yo quiero [I will]" hobbesiano.

El estado de naturaleza es el espacio del juicio radicalmente subjetivo del hombre en torno a los medios considerados necesarios para defender su derecho de preservación; ninguna clase de "protección [protection" y "obediencia [obedience]" es posible mientras prevalezca la diversidad de "opiniones [opinions]" individuales (Schmitt, 1990). Esta diversidad de opiniones hace del estado de naturaleza una modalidad de lazo social ordenada por un perspectivismo ético múltiple; el status naturalis semeja un estado de total anarquía de sentido, las palabras existen en tanto significantes sin significación, carecen de definición palabras como derecho, deber, obediencia, protección, soberano, súbdito, propiedad, religión, etcétera. A ello refiere Hobbes cuando argumenta que el principal obstáculo para una convivencia pacífica reside en los "juicios particulares [particular judgements]" de los hombres sobre las modalidades de garantizar una convivencia humana que asegure su propio derecho de autoconservación.

El abandono del estado de anarquía exegética se produce cuando se constituye un poder común, instituido a través de pactos mutuos fundados en la ley natural que obliga a cada cada hombre a preservar su vida, a los efectos de sancionar el significado de todos los "nombres [names]" -significantes- asociados a la preservación del orden político. Así se forma un poder público cuya tarea es eliminar la polisemia de aquellas palabras pertenecientes al campo de la política. Se constituye, entonces, una "persona [Person]" política autorizada a definir y garantizar el sentido de las palabras del vocabulario político, tornándolas en leyes positivas: el soberano. Pertenece al poder soberano, pues, el 
derecho de "prescribir las normas" que sancionen el significado de la palabra propiedad, libertad, bueno, malo, legItimo, ilegítimo, justo, injusto, etcétera.

El poder soberano deviene así una "re-presentación de la palabra" de los súbditos en la medida que éstos últimos han acordado transferirle su capacidad de nominación al primero. En el estado de naturaleza el perspectivismo subjetivo impedía la conformación de la "significación por convencionalismo" de las palabras claves del orden políticonormativo. La única probabilidad de eliminar el estado de incertidumbre, a los efectos de preservar el derecho de autoconservación, radica en la construcción de un yo decisionista, quién determinará y fijará el significado de aquellas palabras necesarias para el mantenimiento del orden del espacio político. Por tal razón, para "gobernar por medio de palabras es preciso que éstas se den a conocer de modo manifiesto, pues de lo contrario no son leyes" (Hobbes, 1991). La salida del estado de guerra es, entonces, un acuerdo para estatuir una persona soberana, cuyas acciones están libres de cualquier impedimento externo que obstaculize su desarrollo, a los fines de definir el significado de los significantes políticos convirtiéndolos en leyes. De esta manera, el soberano representa a los súbditos porque en la acción de nominar ejecutada por el primero se hace presente la palabra de los últimos.

La diversidad del perspectivismo axiológico se condensa en la "unidad del representante [Unity of the representer]", contraparte de la no "unidad de los representados [Unity of the Represented]". La representación es el modelo que permite el pasaje desde el subjetivismo judicativo hacia el poder artificial que monopoliza el significado de las palabras centrales para la conservación del orden político.

Al desplazar el escepticismo cartesiano al campo de la política, Hobbes niega la existencia de un fundamento ético objetivo y exterior al proceso de evaluación subjetiva realizado por cada individuo. Demuestra así la inexistencia de un fundamento objetivo para la conformación de la 
ley positiva, cuyo imperio debiera regular el comportamiento de los miembros de la comunidad política. La autonomía del sujeto gira en torno a la evaluación ética que cada uno realiza conforme a su derecho de autopreservación. De esta manera la capacidad de autolegislarse que define la libertad del sujeto -su derecho a autoconservarse- impide la convivencia entre los hombres, y, por ende, la conformación del orden de la comunidad política. En este punto es indudable que Hobbes está planteando la posibilidad de salida del estado de naturaleza como el problema de la constitución de una soberanía de características absolutamente novedosas. La soberanía hobbesiana deberá solucionar un problema de corte netamente ideológico (Tuck, 1991): se abocará a la creación del significado de aquellos significantes nodales que definen las normas de convivencia política, nominará el significado de las reglas del derecho constitucional, en suma, inventará un orden social.

A consecuencia de lo expresado llega a término el axioma fundante de la formalización hobbesiana del sujeto politico qua sujeto de la decisión: Auctoritas, non veritas, facit legem. A diferencia del sustancialismo ético-político premoderno garante de un valor trascendente al orden comunitario -sea éste la idea de bien platónica o de felicidad eterna de corte tomista-, el mundo del hombre hobbesiano carece de entes morales de los cuales se pueda predicar su inmutabilidad, su eternidad, su unicidad, su existencia por sí, en suma, su carácter de fundamento. Se deduce entonces que no es factible la existencia de enunciados verdaderos sobre el orden moral debido a su inmanente inestabilidad, motivo éste que coloca al sujeto político en el lugar de la invención normativa, cuya validez reside ahora en la propia acción legislativa ejecutada por una autoridad soberana completamente desvinculada de toda sujeción exterior a su propia decisión. 


\section{II}

Frente a la temática del orden o de la conservación de la comunidad política, el pensamiento de Marx erige al conflicto político como cuestión central para el estudio de la política. Considera que, más allá de las diversas manifestaciones del conflicto, existe una dimensión específica común a ellas; a saber, la violencia, un elemento consustancial a las relaciones sociales desarrolladas en todo orden político. En cuanto elemento de mediación de las relaciones sociales, Marx piensa a la violencia como parte de una ontología de lo político en la cual ésta se presentifica por vía del conflicto de clases. Visto desde esta perspectiva, la temática marxiana pareciera instalarse en el polo opuesto a un pensamiento político dirigido a descubrir las razones del mantenimiento del orden interior de la comunidad. En tal sentido el protagonismo de la "violencia [Gewalt]" permea sus textos centrales, haciendo del conflicto político y las relaciones sociales el par conceptual característico de su concepción de la política: acciones de agrupamientos de clase recíprocamente orientadas a través de la violencia -i.e. dimensión política de la lucha de clases.

Las relaciones entre clases reconocen un doble nivel de articulación referido a las diferencias que se presentan entre el espacio social de las relaciones de producción y el espacio político del antagonismo político. Mientras que en el espacio social las clases sociales representan las posiciones de sujeto estructurales que los agentes sociales ocupan en el proceso de trabajo y en el proceso de valorización -y, donde el sujeto qua actor social individual desarrolla acciones orientadas por las expectativas de comportamiento de otro actor en el ámbito de una determinada institución-, en el espacio político las clases sociales nombran a los sujetos de acción colectiva constituídos bajo la forma de identidades de clase polemógenas, esto es, al sujeto colectivo cuya acción respecto a la otredad es regida mediante la lógica amigo-enemigo. De esta forma al carácter 
contradictorio que define las relaciones entre propietarios de mercancías en el espacio de lo social le corresponde la lógica de la enemistad que rige las identidades colectivas de los agrupamientos humanos en el espacio de lo político. Es así como el antagonismo se coloca en el centro del proceso de conformación de las identidades políticas en la medida que a partir de éste cobra forma el pasaje del sujeto individual al sujeto colectivo.

La concepción del sujeto formalizada por el pensamiento de Marx cambia el escenario de emergencia de la subjetividad; abandona el concepto de status naturalis hobbesiano para instalarse sobre un nuevo horizonte exegético: i. e., la "sociedad fundada en el antagonismo de clase [Klassengegensatz begrundeten Gesellschaft]" (Marx, 1974). Esto supone reemplazar una concepción de la subjetividad modelada a través de la idea de un individuo autónomo y autocentrado por una visión del sujeto centrada en la "clase social [sozial Klasse]". Se prescinde, pues, de una subjetividad definida en clave ético-antropológica -la concepción de un hombre qua sede de derechos inalienables- a fin de colocarse en una perspectiva teórica que hace del sujeto un concepto sociológico colectivo: la clase social. Para Marx, "el hombre [Mensch] no es un ser [Wesen] abstracto [abstraktes]"; por el contrario, él es el "mundo de los hombres, es el Estado [Staat], la sociedad [Sozietat]” (Marx, 1982a). Así el individuo autónomo fundado sobre el yo se disolverá en favor de un sujeto de carácter colectivo: ahora "la esencia humana [menschliche Wesen]" del "individuo" no es otra cosa que el "conjunto de las relaciones" entre clases sociales.

En los escritos de Marx, el análisis de la subjetividad gira en torno a su concepción de lo político, pero abandonando la argumentación del pensamiento que de Hobbes a Hegel intentaba justificar al Estado como la forma más acabada de convivencia racional. Sin embargo, tomado por esta fundamentación del Estado moderno, Marx participa en sus primeros ensayos de los tópicos clásicos del pensamiento polítıco que se desarrollan entre los siglos XVII y XIX. Contemporáneamente al "gran 
descubrimiento de Copérnico sobre el verdadero sistema solar" comenta Marx-, el pensamiento político "descubrió la ley de gravitación del Estado, se encontró la gravedad en él mismo ... [Maquiavelo, Hobbes, Rousseau, Hegel] comenzaron a ver el Estado con ojos humanos y a desarrollar sus leyes partiendo de la razón y de la experiencia, y no de la teología ..." (Marx, 1982b). Junto a este fundamento secularizado del Estado moderno aparecía una concepción del sujeto como yo autónomo, sede de la "libertad general de la naturaleza humana". Inscripto en esta perspectiva exegética de raigambre humanista, Marx afirma: "el individuo ciudadano del Estado obedece en las leyes de éste sólamente a su propia razón, a la razón humana" (Marx, 1982c). Paralelamente a esta concepción de la subjetividad centrada en un yo autónomo y racional, Marx piensa la relación entre el sujeto y la comunidad política a modo de proceso pedagógico, a través del cual el Estado "educa a sus miembros ... al convertir los fines individuales en fines generales ... la independencia natural en libertad espiritual" (Marx, 1982d).

Cuando poco tiempo después Marx afirme que "la vida política sólo tiene por misión garantizar los derechos humanos, los derechos del hombre individual" (Marx, 1982e), habrá desaparecido la idea de un "interés general [allgemeine Interesse]" como fundamento y "fin del Estado [Zweck des Staat]". El Extra reipublicae nulla salus, que guía el pensamiento de Hobbes y del modelo iusnaturalista, será desplazado por el "bellum omnium contra omnes"; idea que a Marx le permitirá posteriormente ingresar al espacio político-social el conflicto social, dañando de raíz la eficacia del soberano hobbesiano para contener la "disolución del estado" ocasionada por la "guerra civil".

Una de las más tempranas aproximaciones del pensamiento de Marx a la noción de sujeto político qua clase social (Marx, 1982a) presupone la forma del conflicto antagónico, asociado a la existencia de una clase de la "sociedad civil" nacida de la "pobreza artificial" generada 
a causa del desarrollo de la industria moderna: el "proletariado". Sujeta a "cadenas radicales", esta clase social, "que representa, en una palabra, la pérdida total del hombre", está destinada a llevar a cabo la emancipación total del hombre en general, a través del "combate" entre agrupamientos humanos, cada uno de los cuales reconoce en el otro a su "enemigo". Si bien la clase social que lleve a cabo la revolución está caracterizada desde una perspectiva ética, Marx considera que tal situación de miseria es producto de las modernas condiciones sociales instaladas por el proceso de industrialización.

Desde esta perspectiva, la constitución del sujeto político posee dos predicados básicos, a saber: en primer término, la enemistad inherente al conflicto entre agrupamientos humanos $y$, en segundo término, la pobreza y riqueza de las clases sociales, producida por el "movimiento industrial". En efecto, la reflexión marxiana reconoce dos espacios para pensar la emergencia de las identidades de los sujetos políticos: la esfera de la sociedad civil, donde las clases son definidas desde las dimensiones de la riqueza y de la pobreza creadas artificialmente, por un lado, y la arena del conflicto político, que rige la relación entre agrupamientos humanos según la lógica amigo-enemigo. La ligazón social fundante de la conformación del proletariado es un "interés" representado bajo la forma de "la negación de la propiedad privada", de cuya abolición resulta necesariamente el tránsito hacia una sociedad que realiza el principio de "la emancipación humana", de "la recuperación total del hombre".

El análisis de Marx resemantiza lo político al considerarlo desde una perspectiva polemógena, al postular que todo intento por instalar un orden público que excluya el conflicto entre los miembros de la comunidad es imposible. De esta forma, se produce la escisión de la unidad del estado político moderno -ya sea ella expresada mediante el moi commun de Rousseau o a través del politique body" de Hobbes- debido a que "[t]oda la sociedad [Gesellschaft] va dividiéndose [spaltet sich] cada 
vez más en dos grandes campos enemigos [in zwei grosse feindliche Lager], en dos grandes clases, que se enfrentan directamente: la burguesía [Bourgeoisie] y el proletariado [Proletariat]" (Marx, 1977).

La completa imposibilidad de toda comunidad política por constituirse en un orden institucional estable es la condición necesaria para la emergencia de identidades colectivas polemógenas. Expresado en otros términos, la imposibilidad de emplazar un ordenamiento político determinado supone la virtualidad del conflicto entre agrupamientos humanos colectivos, cuyas identidades han sido constituidas mediante un proceso de enemistad especular. El fracaso del proceso de institucionalización del ordenamiento normativo, de la estructuración de una convivencia humana racional en el interior de la comunidad política condujo al pensamiento marxiano a formalizar un sujeto de nuevo tipo. De este modo la concepción marxiana de la subjetividad difiere de aquélla definida por el pensamiento político y social iusnaturalista porque rechaza representar al sujeto como un yo autónomo, individual, un hombre portador de una naturaleza humana universal.

La cuestión del sujeto se traduce -para Marx- en el problema de la modalidad adoptada por el proceso de constitución de una subjetividad de tipo colectivo, cuya construcción supone una relación de reconocimiento especular, enmarcado dentro de una forma de relación social de conflicto. Mientras que en el pensamiento hobbesiano el desplazamiento de la "guerra civil [Civill Warre]" garantizaba el derecho natural del hombre a su preservación -bajo la forma de un yo autónomo, en Marx la "guerra civil [Burgerkrieg]" es el momento culminante del proceso de constitución de la identidad de la clase social. Al inaugurar una forma de concebir las identidades colectivas en donde cada uno de los sujetos sociales se representa al otro qua "enemigo [Feind]", la lógica de la enemistad hace que los sujetos sociales cobren identidad mediante la guerra, entendida como "lucha de clases [Klassenkampf]". 
Ausente el sustento común que cohesiona al cuerpo político, se produce la formación de identidades subjetivas polemógenas dentro del espacio político. Aun cuando las clases sociales nacen en el terreno de la "sociedad civil [burgerliche Gesellschaft]", adquieren identidad de sujeto al conformarse como agrupamientos humanos enemigos en el campo de lo político, sustentados sobre una representación común y colectiva del "interés de clase [Klasseninteressen]" (Marx, 1974).

Aparece de esta manera la determinación de lo político recortando la formación de la identidad de los agrupamientos humanos sobre un espacio regido por la "violencia [Gewalt]": la identidad del sujeto se determina partiendo de una agonística fundante de todo nexo entre agrupamientos humanos. Perdida la convivencia pacífica entre los miembros de la asociación política y desplazada la representación de un interés general, lo político se transforma en el espacio donde emergen las identidades de sujeto matrizadas por la lógica del conflicto amigo-enemigo. La violencia recíprocamente referida entre asociaciones humanas permite la constitución de las identidades de clases basadas en intereses antagónicos.

La virtualidad de una dualidad polemógena entre agrupamientos humanos de clase, otorga a cada una de sus identidades un sentido existencial, debido a que la presencia de cada una de ellas supone la negación de la restante (Schmitt, 1984); ambas yacen en una relación de especularidad dual que excluye completamente la participación de un tercero en tanto árbitro. Debido a que la enemistad es inmanente a la lógica de constitución de las identidades colectivas de clase, éstas y la violencia forman -según Marx- un par conceptual inescindible; en suma, todo agrupamiento humano colectivo funda su subjetividad sobre una permanente lógica agonística.

Las identidades de sujeto no son aquí, al igual que en el iusnaturalismo, datos lógicamente anteriores al espacio político; por el contrario, éstas son comprendidas como parte de un proceso de constitución desde el cual Marx privilegiará el análisis de la 
conformación de la identidad del proletariado. La concepción marxiana de la subjetividad refiere a la emergencia del sujeto social como un proceso de constitución; aquél en el cual se produce la "conformación del proletariado en clase [Bildung del Proletariat zur Klasse]". Esta conformación consiste en continuos "ensayos de los trabajadores [Versuche der Arbeiter]" con el fin de "asociarse [sich assoziieren]" en agrupamientos humanos que toman la "forma de coaliciones [Form von Koalitionen]" (Marx, 1974).

En principio, los trabajadores -según Marx- no son más que una "masa [Mengue] de gentes desconocidas [unbekannter Leuten] entre sí" (Marx, 1974), que sólo comparten el permanecer reunidos en un mismo "lugar [Ort]" geográfico, a consecuencia del desarrollo de la "gran industria [Grossindustrie]". No obstante, el "sostenimiento del salario [Aufrechterhaltung del Lohnes]" los "liga [vereinigt]" mediante una "común representación de' resistir [gemeinsamen Gedanke des Widerstandes]" (Marx, 1974); ello conforma un primer "interés común [gemeinesame Interesse]" sostenido "contra" el "patrono [Meister]" . En este momento de su proceso de constitución el sujeto social deviene "coalición [Koalition]", esto es, un modo de organización por el cual los "trabajadores" abandonan su relación de mutua competencia para llevar a cabo una "competencia general [allgemeine Konkurrenz] contra los capitalistas [Kapitalisten]".

Con posterioridad y de resultas de la "represión [Repression]" ejercida por los "capitalistas", las "coaliciones aisladas [isolierten Koalitionen]" se unifican en 'grupos [Gruppen]" cuya "representación común", es ahora el "sostenimiento de la asociación [Aufrechterhaltung der Assoziationen]". El despliegue de esta lógica de enemistad especular conduce a una total "escisión [spalten]" de la comunidad política; consecuentemente, el espacio público deviene en "guerra civil [Burgerkrieg]" entre clases, organizadas como "coaliciones de carácter político [politischen Charakter]" (Marx, 1974). 
En la formalización marxiana, la concepción de la subjetividad adopta la modalidad de un proceso de producción que prescinde de la idea de un sujeto autónomo y refractario respecto del espacio político -el sujeto del iusnaturalismo-, al tiempo que demanda la presencia de un otro o semejante que lo reconozca en su identidad diferencial. Asimismo dicho proceso supone, en un principio, que la primitiva "conformación [Bildung]" del sujeto social es producto de la operación que Marx imputa al propio desarrollo de la "relaciones económicas [okonomischen Verhaltnisse]" capitalistas las cuales han transformado a la "masa [Masse] del país en trabajadores [Arbeiter]". Esta masa puede comprenderse como el punto de partida en la constitución de la subjetividad colectiva, a causa de estar conceptualizada en Marx a la manera de un agrupamiento humano formado a partir de una "situación común [gemeinsame Situation]", esto es, a una "representación común [gemeinsame Gedanken]": los "intereses comunes [gemeinsame Interessen]".

La representación de los intereses comunes es -para Marx- una determinada posición subjetiva, porque la "masa [Masse]" como "clase frente al capital [Klasse gegenuber dem Kapital]" implica ya un primer recorte de la identidad colectiva del sujeto, comparada con las primeras formas de lucha llevadas a cabo por una "masa disgregada [zersplitterte Masse]". El "interés común" está condensado en la "representación" que agrupa a los "trabajadores" en pos del "sostenimiento del salario" y en contra de la "dominación [Herrschaft des Kapital]". A este momento de constitución de la subjetividad corresponde un sujeto que todavía no se encuentra claramente fijado a una "representación" estructurada bajo la forma de "intereses de clases [Klasseninteressen]": es ésta una posición de sujeto donde la clase no es aún para si misma [für sich selbst]". Aunque aquí exista ya una posición subjetiva de clase, la coalición de los "trabajadores" no está regida por una "representación" de su "propia unidad [eigenen Vereinigung]"; por el contrario, los trabajadores están agrupados como 
consecuencia de su oposición a la "unidad de la burguesía [Vereinigung der Bourgoisie]".

Desde el momento en que la posición subjetiva se organiza mediante una "representación" de su "propia unidad" surge el sujeto definido "como clase para sí misma [als Klasse für sich selbst]". Llegados a este punto de constitución de las identidades, la "propia unidad" alcanzada por las dos posiciones subjetivas quedan estructuradas a través de la "oposición [Gegensatz]", mediante la que los sujetos se reconocen qua "enemigos [Feinde]". Resulta de ello que la "totalidad de la sociedad se escinde [ganze Gesellschaft spaltet sich]" en dos posiciones de sujeto determinadas por la enemistad: el espacio político se transforma, entonces, en "guerra civil [Burgerkrieg]".

Entre el estado de disgregación y desconocimiento en que se encuentran los "trabajadores [Arbeiter]" y la "unidad" de los mismos expresada por la noción de "clase para sí [Klasse für sich selbst]" media el desarrollo del proceso de constitución de la subjetividad de corte colectiva. En este "proceso [Bildung]" los diferentes grados de agrupamiento -i. e., las "coaliciones [Koalitionen]"- están organizados mediante un determinado tipo de "representación [Gedanke]", siendo ésta "común [gemeisame]" a los miembros de la misma: la identidad de sujeto se construye a partir de "representaciones" sociales", expresado en otras palabras, todo sujeto colectivo define su identidad al emerger en el campo político portando una "representación" específica. En efecto, no hay subjetividad colectiva sin representación, en la medida que es ella quién sostiene la identidad colectiva del agrupamiento humano; consecuentemente, subjetividad y representación se presuponen mutuamente en el proceso de constitución de las identidades colectivas. Incluso la relación social de características polemógenas se comprende en tanto la misma está mediada por un reconocimiento recíproco de la representación con la que cada sujeto colectivo se constituye como tal. La representación social esta supuesta en la "lucha [Kampf]" entre burguesía 
y proletariado, posibilitando que se instale el "antagonismo [Gegensatz]" entre clases a la manera de una enemistad especular irreductible. De este modo, en toda sociedad "fundada [begrundete]" sobre la "oposición de clases [Klassengegensatz]", la "constitución [Bildung]" de posiciones subjetivas adoptará la forma de un reconocimiento polemógeno entre representaciones heterogéneas. En este sentido, el campo político se presenta como la arena sobre la cual la lógica amigo-enemigo- se transforma en una "contradicción brutal [brutalen Widerspruch]" entre representaciones colectivas de sujeto.

La lógica de constitución de las identidades políticas reside en el tránsito que se desarrolla desde la subjetividad del agente, cuya conducta se desarrolla en la estructura económica de la sociedad, -donde las clases son determinadas por la lógica del proceso de valorización del capital-, hacia el sujeto colectivo que emerge en el campo del antagonismo político de clases. Ya sea una lucha entre opresores y oprimidos o burguesia y proletariado, el antagonismo nombra el momento de constitución de una identidad a partir de aquella otra cuya única característica identitaria es presentarse como la negación de la primera, en el campo de las representaciones sociales. El antagonismo es la construcción de una representación del espacio político bajo la forma de la enemistad identitaria especular entre sujetos de acción colectiva dentro del mundo social transformado por el capitalismo industrial. Conflicto político y régimen capitalista son los extremos de una relación mediada a través del antagonismo entre coaliciones de clases, las cuales tienden indefectiblemente a polarizar el espacio de la comunidad, impugnando el recurso de un tercero -el estado- que neutralice la bipolaridad. Lo político es el campo de batalla donde se construyen las identidades de los diversos agrupamientos humanos por vía de la posibilidad de actualizar un permanente estado de guerra civil, suscitado por la amenaza recíproca que cada identidad colectiva representa para la otra. 
$\mathrm{Si}$ comparamos los diferentes tipos de representaciones que circulan en el espacio social y en el espacio político podemos afirmar que la lucba de clases qua lucha política es un antagonismo exterior al proceso de producción de valor. Las representaciones sociales que caracterizan el proceso de intercambio entre propietarios de mercancías, y cuyo contenido está dado por el conjunto de derechos del hombre y el ciudadano, son sustantivamente distintas a aquellas otras fundadas sobre intereses colectivos de clase, debido a que cada una de ellas supone identidades de sujeto completamente diferentes: i.e., el sujeto individual del mercado y el sujeto de acción colectiva de la política. La concepción de la marxiana abandona la subjetividad del yo para interrogarse sobre la subjetividad colectiva, desplazando a la primera al espacio de las representaciones de los agentes sociales, quienes en la esfera de la circulación intercambian mercancías y se reconocen como propietarios. La mencionada afirmación lo conduce a rechazar cualquier concepción de la identidad basada en un proceso autoreflexivo e introspectivo; por el contrario las identidades sociales deben pensarse como el producto de un proceso de reconocimiento entre subjetividades antagónicas. Desde esta perspectiva el modelo marxiano de las identidades políticas rechazaría no sólo el polo de una identidad individual de sujeto -el yo individual de la economía política-, sino también aquel tipo de identidad comunitaria que postularía una representación común a la totalidad de los miembros de un cuerpo político -el yo común rousseauniano.

Marx introduce, consecuentemente, un elemento central al modelo de indagación de las identidades políticas que desconstruye toda lógica de la mismidad: i.e., el antagonismo, noción mediante la cual la identidad aparece siempre a modo de una identidad situada en relación a otra que se presenta como su pura negación. Sólo mediante la negación como lógica antagónica se torna posible la construcción de las identidades, en tanto la interpelación al otro qua enemigo es condición para la conformación de la identidad propia. Siendo el espacio político intrínsecamente antagónico 
debido a su producción de identidades necesariamente polemógenas, el modelo marxiano de las identidades rechaza toda concepción de la política dirigida al estudio de los problemas del orden o de la par, por el contrario, argumenta que el fundamento de lo político reside en la schmittiana distinción amigo - enemigo.

En "los tiempos modernos -leemos en La ideologia alemana- es el [antagonismo] que existe entre burguesía y proletariado" (Marx \& Engels, 1985) aquel en el cual cobra forma el conflicto polemógeno entre los sujetos políticos. Marx iguala nuevamente los conceptos de "antagonismo entre clases", "coalisiones entre diversas clases" y "lucha politica" a los efectos de referirse a la constitución de identidades de sujeto, partiendo de un modelo de relación social en el que las clases sociales despliegan acciones colectivas reciprocamente referidas fundadas en la enemistad.

El Prólogo del '59 es el texto que expresa con mayor claridad las dimensiones de la constitución del sujeto político sobre la base de dos niveles de estructuración de las relaciones sociales: las clases nombran, por un lado, la distribución de los agentes entre las posiciones de sujeto estructurales de las relaciones sociales de producción y, por otro, la constitución de las posiciones de sujeto colectivo correspondientes a las relaciones politicas de enemistad. Para Marx, "los hombres establecen determinadas relaciones, necesarias e independientes de su voluntad" que conforman "la estructura económica de la sociedad, la base real sobre la cual se alza un edificio jurídico y político, y a la cual corresponden determinadas formas de conciencia social (...) dentro de las cuales los hombre cobran conciencia del conflicto y lo dirimen" (Marx, 1982f).

Al utilizar la noción de formas de conciencia social, Marx tiene en mente aquel tipo de representación social que permite la ligaqón de los individuos entre sí en tanto y en cuanto comparten un mismn rasgo de significación: i.e., la representación del interés de clase. Por ende, la guerra civil entre clases sociales supone formas polemógenas de conciencia social que 
re-presentan el rasgo identitario de los sujetos de acción de acción colectiva. Así, mientras capital y fuerza de trabajo son las determinaciones fundamentales de las clases sociales desde la perspectiva de la estructura económica, burguesía y proletariado representan las determinaciones identitarias de las clases sociales en el campo de la constitución de las identidades colectivas. En el pensamiento marxiano, el conflicto violento es un elemento fundante de la identidades políticas en la medida que el principio de conformación de los agrupamientos sociales únicamente allí alcanza su completo desarrollo. El conflicto político es el dominio en el que las clases sociales como agrupamientos humanos devienen sujetos politicos de acción colectiva, cuyo principio de cohesión interna se contruye a través de una representación común basada en un rasgo de significación que interpela al otro como enemigo.

\section{III}

Ubicada sobre el campo de los problemas abiertos por la llamada crisis del marxismo la indagación de Laclau pretende redefinir teóricamente las identidades colectivas, sometiendo a crítica los postulados sustancialistas de la exégesis marxiana: la "crisis del marxismo" no es sino la crítica dirigida al "paradigma político esencialista del marxismo clásico". Frente al apriorismo marxiano que considera la conformación de las identidades sociales desde un modelo basado en la correspondencia entre agentes sociales e intereses objetivos, sumado a la interpretación de un antagonismo social centrado en la existencia de un sujeto universal -la clase social-, Laclau conduce su trabajo hacia la comprensión de una escena social signada por "la emergencia de nuevos antagonismos" (Laclau \& Mouffe, 1987). La difusión de una multiplicidad de identidades nuevas y diferentes a la clase social conlleva necesariamente la reconceptualización de la noción marxiana de 
sociedad. "Esta proliferación de luchas se presenta, en primer término, como un exceso de lo social en relación a los cuadros racionales y organizados de la sociedad -esto es, del orden social" (Laclau \& Mouffe, 1987). La pluralidad de los conflictos contemporáneos cuestiona "la centralidad ontológica de la clase obrera"; la formación de "una voluntad colectiva perfectamente una y homogénea" desaparece. Significa ello impugnar toda concepción teórica sustentada en "el supuesto de la sociedad como una estructura inteligible, que puede ser abarcada y dominada intelectualmente a partir de ciertas posiciones de clase y reconstituida como orden racional y transparente a partir de un acto fundacional de carácter político" (Laclau \& Mouffe, 1987). La dispersión del conflicto elimina cualquier intento racionalista por aprehender la diversidad de lo social mediante la utilización del concepto totalidad; noción que permite pensar la articulación de los distintos niveles de las prácticas sociales bajo la forma de una estructura regida desde un centro único que la torna inteligible: -i. e., el devenir histórico-social interpretado en clave contradicción entre fuerzas productivas y relaciones de producción. La ausencia de un núcleo de sentido omnicomprensivo obstaculiza, en consecuencia, la pretensión de conocer a priori el significado de las prácticas de los sujetos colectivos. En oposición a las interpretaciones sustentadas en la determinación de los rasgos permanentes de todo orden social, la indagación de los sentidos que atraviesan el campo social está dada por el antagonismo y la contingencia que domina a las identidades de sujeto. Negada la centralidad del conflicto de clases resultante de la emergencia de una pluralidad de antagonismos, es rechazada "toda prerrogativa epistemológica fundada en la presunta posición ontológicamente privilegiada de una clase universal". Por ende, al criticarse el concepto de totalidad social y, consecuentemente, la existencia de una perspectiva epistemológica privilegiada, "[n]i la concepción de la subjetividad y de las clases que el marxismo elaborara, ni su visión del curso histórico del desarrollo capitalista, ni, desde luego, la concepción 
del comunismo como sociedad transparente de la que habrán desaparecido los antagonismos, pueden seguirse manteniendo hoy" (Laclau \& Mouffe, 1987).

Los antagonismos sociales muestran una pluralidad de identidades colectivas que han terminado por desbordar los "cuadros racionales y organizados de la sociedad ... por disolver el fundamento último en el que se basaba este imaginario político [marxiano], poblado de sujetos universales ..." (Laclau \& Mouffe, 1987). Laclau inscribe sus ejes de indagación en el contexto del debate dominado por dos cuestiones teóricas de importancia fundamental: en primer lugar, el problema de los límites del conocimiento de las ciencias humanas $y$, en segundo término, la discusión sobre la relación entre sujeto y estructura. En referencia al primero de ellos, sostiene que la erosión de la creencia en la ilimitada capacidad de la razón -expresada en una conciencia moderna que evaluaba todo advenimiento de lo nuevo qua bueno per se en el marco de la "promesa de un futuro ilimitado"- ha paulatinamente instalado la "conciencia de los límites de la razón" en el terreno de la historia de las ideas, impactando, a la vez, directamente sobre el cuerpo de una teoría social acostumbrada a representarse a la sociedad como una totalidad esencialista, objetiva y racional. Respecto a la segunda cuestión, se trata de uno de los debates correspondiente al período mencionado en cuanto gira alrededor de la manera de interpretar las relaciones sociales: éstas se pueden comprender desde la lógica de la estructuras o, contrariamente, desde la lógica del sujeto. Frente a este interrogante de la teoría social, la reflexión de Laclau pretende colocar la discusión sobre la relación entre estructura y sujeto en términos completamente diferentes a los habituales, y a tal fin enuncia dos hipótesis que serán capitales en sus estudios. Laclau postula que tanto la conformación del orden social como la constitución del sujeto son incompletos, sus respectivas identidades son contingentes y precarias, en suma, les resulta imposible adquirir una forma plena y completa: la característica principal de ellas es 
su inconsistencia. Su formalización de la emergencia de las identidades colectivas inhabilita de igual manera una concepción tanto subjetivista como otra de corte objetivista. En efecto, Laclau no adhiere ni a un pensamiento centrado en el actor hacedor del orden institucional, ni tampoco a una versión determinista que asimile al agente a un efecto de estructura. Sin embargo, no abandona ninguno de éstos conceptos de teoría social; sujeto y estructura resultarán fundamentales para concebir una modalidad de interpretación de lo social que, escapando al paradigma subjetivista y objetivista, ofrezca no sólo una nueva versión de la articulación de los mismos, sino también una redefinición completamente diferente de las mencionadas nociones. Al repensar la dicotomía de éste clásico par conceptual de las ciencias sociales, Laclau elabora una respuesta en la que formaliza una nueva concepción del sujeto y de la estructura; tarea ésta que supone la desconstrucción del modelo marxiano de sujeto mediante el uso de una gama de problemas, enfoques y conceptos pertenecientes a tradiciones teóricas de distinta raigambre, cuya característica común es la crítica a las concepciones esencialistas del sujeto -e.g. la filosofías de Nietzsche y de Heidegger, la lingüística de Saussure y el psicoanálisis de Freud y Lacan.

Cotejada con los planteos de Hobbes y Marx, la estrategia de Laclau postula que tanto el sujeto como la estructura son por definición incompletos; dicho de otro modo, no existe sujeto que pueda aspirar a una identidad plena ni, tampoco, un orden social completamente estructurado sobre sí mismo. En su concepción teórica la representación plena del sujeto y la completa sistematicidad de la sociedad pertenecen al orden de lo imposible, a causa de la carencia de estabilidad y consistencia debida al antagonismo inmanente a las relaciones sociales. El programa de Laclau intenta elaborar una teoría de las relaciones entre sujeto y estructura desde una óptica antisustancialista, donde la incompletud, la escisión y la falta definan no solamente las propiedades fundamentales de ambos términos, sino también la posibilidad misma de articulación 
entre ellos mismos. Pensar al sujeto y a la estructura a partiendo de la lógica de la inconsistencia supone, pues, impugnar tanto al sujeto centrado de la tradición cartesiana como al devenir teleológico del orden bistórico-social de la tradición hegelo-marxiana.. El interés de Laclau será demostrar la imposibilidad del orden social de tornarse un orden objetivo y la imposibilidad del sujeto para devenir una identidad completa, afirmando, así, el agotamiento de la concepción teórica asentada sobre una ontología de la presencia, ya sea que ésta adopte la forma de una metafísica o bien de la subjetividad o bien de la estructura histórico-social. Ello desestima la visión de un sujeto que es permanente presencia, sustantivo, autosuficiente y rechaza tanto una subjetividad individual centrada sobre sí como una subjetividad colectiva producida en la estructura social. Laclau erradica cualquier certeza subjetiva u objetiva que pretenda oficiar de garante último de la identidad del sujeto o de la estructura históricosocial. La estructura social no es una entidad autónoma de dependencia interna que, edificada sobre un fundamento esencialista, otorga sentido a todos y cada uno de los niveles que la componen; en efecto, la sociedad no debe pensarse como una sustancia autónoma, presente y aprehensible racionalmente mediante el descubrimiento de sus leyes rectoras. A diferencia de esto, la sociedad es una estructura contingente, un ordenamiento social cercado por la posibilidad permanente de dislocación, por un des-orden introducido mediante el antagonismo social; así al "renunciar a la concepción de la sociedad como totalidad fundante de sus procesos parciales" se niega la existencia de una esencia social que fija las relaciones entre las partes constitutivas de la totalidad social. La sociedad es, en cambio, la posibiliad de construcción de un orden social completo y estructurado, producto de "intentos precarios y en última instancia fallidos de domesticar el campo de las diferencias ... [que caracteriza] la multiformidad de lo social ... [desestimando la idea de que] el orden social [pueda] ser concebido como un principio subyacente" (Laclau \& Mouffe, 1987). En esta línea la sociedad qua orden estará 
siempre jaqueada por un determinado "exceso de lo social" inmanente a ella: tal exceso no es sino el antagonismo social, un límite que no cesa en su tarea de dislocar el ordenamiento social. La sociedad no es sino un conjunto de relaciones sociales articuladas de manera precaria, esto es, una "sutura" contingente de la "multiformidad de lo social" carente de esencia. El espacio social es, entonces, el proceso de articulaciones precarias y contingentes de sus elementos, sin referencia a ninguna sustancialidad o fundamento societal.

Impugnado el modelo totalizador de la topografía marxiana de base-superestructura y, consecuentemente, el modelo de constitución de las identidades de clase, Laclau propone indagar la conformación de los sujetos sociales según el modelo de la lingüística saussureana, poniendo en contacto el problema de la subjetividad con los aportes del denominado giro lingüístico. El estudio de las identidades sociales se instala sobre las coordenadas de las principales tesis de la lingüística debido a que el carácter relacional de la totalidad representada en la lengua, el primado del significante sobre el significado y la naturaleza diferencial de los signos comienzan a ser utilizados en la elaboración de una teoría del sujeto social. Conforme se introduce un modelo diseñado en base a la naturaleza relacional y el carácter diferencial del signo, la constitución de la identidad del sujeto sigue los derroteros de la lógica del significante. Aceptada la concepción antisustancialista de lo social, las identidades sociales de los actores colectivos tomarán la forma de prácticas articulatorias cuya lógica no puede referenciarse en ningún fundamento externo a ella misma. Es, contrariamente, en el terreno de las relaciones establecidas entre los diferentes sujetos donde debe buscarse el momento articulador de la diversidad indentitaria de los actores. La sociedad adquiere, paralelamente, la forma de un sistema relacional de diferencias articuladas precariamente alrededor de un punto nodal dador de "sentido", que otorga un determinado nivel de sistematicidad a la totalidad social a través de la ordenación espacial de las identidades de los sujetos . 
Desconstruído el carácter inmutable, permanente y presente de la topografía marxiana, Laclau postula que es la inconsistencia el rasgo dominante de la estructura y del sujeto; en efecto, la constitución de una identidad plena resulta del orden de lo imposible, en virtud de que el sujeto y la estructura social se conforman sobre los contornos de una falta inherente a sus respectivas identidades. La incompletud que gobierna la lógica del sujeto y del orden social no nombra únicamente la imposibilidad de conformación de una identidad plena, sino también la posibilidad de constitución de una identidad, incluso cuando ésta sea precaria y parcial, comparada con las identidades de los sujetos universales descriptas en el marxismo. La falta constitutiva localizada en cada uno de los polos que componen la relación conceptual en cuestión es, simultáneamente, la condición de posibilidad para la constitución de sus respectivas identidades. La articulación entre ambos órdenes reviste o la forma de la sutura -proceso de incorporación del sujeto a la estructura social por vía de la identificación- $\mathrm{o}$, inversamente, el modo de la dislocación -proceso de desagregación de los sujetos de la estructura social sobre la que estaban fijados. Es justamente la naturaleza precaria y contingente de la estructura, debida a la infinitud de lo social, la dimensión que hace imposible el cierre o sutura definitiva de la estructura social, evitando, por esta causa, la esencialización del orden por vía del descubrimento de su fundamento. La imposibilidad de la estructura por transformarse en un orden completo reside en la imposibilidad de erradicar el antagonismo social, límite éste que le sustrae la objetividad al sistema social.

El concepto de antagonismo social nombra el lugar de una escisión del orden social, una falta que rehuye ser simbolizada; representa la existencia constitutiva de una "cierta traumática imposibilidad" que hace "vano [el] intento de instituir ese objeto imposible: la sociedad" (Laclau, 1993). Pese a que "todo sistema estructural es limitado", la sociedad supone el establecimiento de una "cierta fijación de sentido" sin la cual sería también imposible todo tipo de práctica recursiva o sedimentada: el 
corolario de dicha necesidad de instituir lo social es la ideología, esto es, la forma simbólica de la "voluntad de totalidad de todo discurso totalizante" (Laclau, 1993). La fisura de lo social es, entonces, aquello que no cesa de no inscribirse en el campo socio-simbólico construido por la ideología, práctica discursiva totalizante que siempre fracasa en su intención de conformar una estructura plena, permanente y globalizadora. De esta manera, la incorporación de la pluralidad de las subjetividades al campo de la estructura simbólico-ideológica será siempre precaria y contingente en la medida que las posiciones de sujeto están expuestas a la dislocación de la estructura social, la cual, careciendo de un fundamento esencialista, fracasa en el pretensión de instituir un espacio de representación objetivo donde los sujetos puedan identificarse con un significante que los represente. Consecuentemente, el fracaso de la estabilidad de las posiciones de sujeto o de la sistematicidad de la estructura resguarda la renovada emergencia del sujeto como sujeto de la begemonia.

Aun cuando sea negada la "sociedad como conjunto unificado por leyes necesarias" $\mathrm{y}$, correlativamente, la conformación de identidades universales plenas, no es correcto postular, inversamente, la existencia sustantiva de las identidades parciales plenas, que previamente eran definidas como elementos identitarios articulados en la estructura, so pena de incurrir en otro género de esencialismo que postularía el "carácter necesario de la identidad" de éstas últimas. Con el propósito de llevar a cabo una completa salida del mecanismo de la esencialización resulta necesario afirmar que así como los elementos no encuentran su plena identidad en el seno de la estructura, tampoco logran constituirla a partir de sí mismos, esto es, como si fuesen entidades autónomas y autocentradas.

Si la identidad de los elementos escapa no sólo al esencialismo de una totalidad que los contiene, sino, a la vez, al sustancialismo de la fragmentación, entonces, habrá que pensar en una lógica que postule la precariedad tanto de la identidad de la estructura como de la identidad de los elementos. En otros términos, la sistematicidad de la estructura y la dispersión 
de los elementos serán los polos de una lógica de lo social entendida como práctica articulatoria constitutiva de las relaciones sociales. La cuestión será, pues, elaborar un enfoque de lo social que nos permita pensar la modalidad mediante la que una "creciente proliferación de diferencias", que desbordan todo sentido único e inmutable de lo social, puedan ser articuladas mediante una práctica que posibilite "fijar esas diferencias como momentos de una estructura articulatoria estable”.

No existiendo una esencia de la estructura social que transmita e informe su sentido inmanente y último a todos los niveles de lo social, y que, por ende, constituya de modo necesario y apriorístico identidades colectivas universales, debe formalizarse una conformación del sujeto que, partiendo de la contingencia e bistoricidad de la multiplicidad de identidades sociales parciales, pueda ser repensada como el producto de la articulación equivalencial entre las mencionadas identidades, devenidas ahora en componentes del sujeto hegemónico. La constitución del sujeto hegemónico es, entonces, el producto de la práctica articulatoria de identidades particulares y diferenciales, las cuales resultan transformadas e incorporadas como momentos a una totalidad estructurada discursivamente, esto es, a una configuración significante: es el pasaje desde la lógica de la identidad de los elementos a la lógica de la identidad begemónica. En efecto, las identidades parciales han pasado a formar parte de una relación articulatoria significante sustentada en la "especificidad del momento relacional en que la articulación consiste".

Nuevamente, la concepción de Laclau rechaza la identidad plena del sujeto y la estructuración completa de la sociedad; ambas realizaciones son del orden de lo "imposible" a causa de la carencia de estabilidad y consistencia resultante del antagonismo social que les es inmanente (Laclau, 1993). Cuestiona la concepción de un sujeto autocentrado y autosuficiente, un sujeto pensado como fundamento del orden normativo -un sujeto con identidad plena- $y$, a la vez, impugna un sujeto colectivo que, a diferencia del anterior, cobre identidad por efecto 
de la estructura -un sujeto cuya identidad deviene plena como resultado de la completud de la estructura histórico-social. Se critican las características de todo sujeto -individual o colectivo, creador o creadoque sea concebido a modo de una identidad consistente, presente y permanente, en suma, de un sujeto cuya identidad adopta las propiedades del subjectum o de la ousia. Descartadas las identidades universales, plenas y estables -clases sociales- y consideradas las identidades particulares, parciales e inestables -movimientos sociales- Laclau propone pensar al sujeto político partiendo del análisis de las identidades como si éstas formaran parte de un sistema de diferencias de naturaleza relacional, partiendo de la idea de "que la negatividad es constitutiva de toda identidad" (Laclau, 1993).

Tomando como punto de partida la naturaleza negativa y relacional de las identidades se desestima absolutamente la existencia de un referente externo a su propia articulación, las identidades son modeladas según la lógica del significante (Lacan, 1985). Esto implica que cada una de las identidades es un significante carente de significación propia, a causa de lo cual demanda articularse a otras identidades en una cadena significante, a fin de poder encontrar una significación. En este terreno se forma el sujeto político, producto de una práctica de articulación operada sobre los significantes identitarios, quienes pierden, en consecuencia, su rasgo diferencial, incorporándose a una cadena de equivalencias de significación, en la que el sujeto begemónico tiene la función de condensar las multiplicidad de las identidades parciales en torno a un punto nodal de sentido universal. El sujeto político hegemoniza las identidades parciales bajo la forma de una cadena asociativa significante, modelando una serie de equivalencias mediante desplazamiento y condensación. La función de totalización es cumplida por un significante que, al perder su identidad particular o significado literal, inicia un proceso de metaforización que le permite crear la representación de la identidad plena de un orden comunitario completo y ausente si se lo compara con la dislocación de la estructura social o satus quo vigente. La 
"función de representación totalizante de ese objeto imposible" -la sociedad plena y ausente- es correlativa al proceso de construcción del sujeto político según reza la fórmula de la "relación hegemónica". De esta manera, si "[h] egemonizar algo significa encarnar en una cierta particularidad una función universal que necesariamente la rebasa", entonces, el sujeto político será una identidad o significante particular que a condición de perder su sentido literal puede llegar a representar el significante de una ausencia, esto es, de un orden social pleno, a los fines de metaforizar y representar la oposición al orden social vigente. El corolario de esta argumentación es, entonces, que en tanto el sujeto político se produce abandonando la representación de la particularidad de su significación literal y adquiriendo la representación de la universalidad de una comunidad completa y ausente el sujeto de begemonía sólo puede ser portador de una identidad escindida (Laclau \& Zac, 1994).

El análisis de las identidades políticas requiere -para Laclaudilucidar dos conceptos fundamentales, a saber: estructura y sujeto, conceptos que se encuentran en una relación de mutua dependencia, formando un nexo de correlación y de reenvíos recíprocos. Expresado en otros términos, no es posible entender la lógica de la estructura sino a partir de la comprensión de la lógica del sujeto y viceversa. Laclau enuncia, entonces, que "la oposición de una sociedad que es, estructuralmente, enteramente determinada y otra que es, en su totalidad, el resultado de la libre creación de los agentes sociales, no es una opocición entre concepciones distintas de la sociedad sino que está inscrita en la propia realidad social" (Laclau, 1993). Esto significa afirmar que la lógica del sujeto de la falta debe formalizarse de manera correlativa a la lógica de la incompletud de la estructura: i.e., "hay sujeto porque hay dislocaciones de la estructura"; en consecuencia, el centro del análisis recae sobre la "juntura" establecida entre la "falta" del sujeto y la "incompletud" de la estructura. 
A los fines de pensar una formalización de la relación de juntura entre el sujeto y la estructura, Laclau importa las nociones de identificación, falta, real y sujeto del corpus freudolacaniano; momento que marca el pasaje del concepto de "posiciones de sujeto" -de corte posestructuralista- hacia aquella concepción de sujeto desarrollada en consonancia con la teoría lacaniana. El hilo conductor de este tránsito puede relevarse mediante las diferentes dimensiones implicadas en el concepto de "identidad" y la noción de "identificación", por tanto, cambio de perspectiva que supone la diferencia de género que reside entre la concepción de "identidad" del sujeto qua "posiciones de sujeto" y la "identidad" del sujeto qua "sujeto de la falta".

Asimismo reflexionar sobre el sujeto de la falta supone estudiar la emergencia de la subjetividad desde una perspectiva que intente pensar aquello que Laclau denomina la presencia de la ausencia: formalizar la constitución del sujeto como el resultado de una falta o carencia inmanente a la propia estructura. En otros términos, Laclau postula que la incompletud o carencia de la estructura es la condición de posibilidad para la constitución del sujeto; aquí está la correlación entre la incompletud de la estructura y la falta en el sujeto, que posibilita a éste último emerger en el lugar de una fisura que presenta el orden social, allí donde un elemento de la misma falta $y$, por ende, muestra su inconsistencia.

El espacio de la incompletud de la estructura y el tiempo de constitución de la subjetividad son dos dimensiones de una misma operación de constitución del sujeto político-hegemónico. Mientras el concepto de falta mienta una falla estructural del orden social existente como espacio de efectuación del nuevo sujeto político, la noción de real, por su lado, semeja la idea de una dislocación imposible de ser incorporada al orden simbólico debido a que es un puro sin sentido carente de todo significante que pueda inscribirlo como tal. 
La incompletud de la la estructura es completamente heterónoma respecto al sujeto, esto es, la fisura de primera se torna visible sólo en el proceso de efectuación del segundo; la producción del sujeto, en consecuencia, no es exterior a la estructura debido a el primero deviene a través de la falla existente en ésta última; no obstante, el sujeto, tampoco, es interior a la estructura en cuanto ésta fracasa en su intento por incorporarlo como el elemento faltante que la completaría definitivamente. Si el sujeto no es ni interior ni exterior a la estructura, si no está ni incorporado ni desujetado plenamente respecto de ella, si no existe una característica precisa que escinda a uno y a otro de los elementos mencionados, en suma, si ambos términos no mantienen una relación delimitada y estable -al modo de entidades autónomas y completamente constituidas- será necesario concebir la articulación entre el sujeto y la estructura bajo la forma del espacio topológico, a fin de abandonar la espacialidad dicotómica fundada en la consistencia de un espacio del interior y un espacio del exterior. Expresado esto pueden plantearse las dos principales modalidades de juntura que ligan el sujeto a la estructura, entendida la última a la manera de una superficie discursiva de significación sobre el cual se desarrolla el proceso de efectuación del sujeto qua identidad por la vía el mecanismo de la identificación. Si bien es lícito afirmar respecto del sujeto -sostiene Laclau- que "[]]a dislocación es la fuente de la libertad ... ésta no es la libertad de un sujeto que tiene una identidad positiva -pues en tal caso sería tan sólo una posición estructural- sino la libertad derivada de una falla estructural, por lo que el sujeto sólo puede construirse una identidad a través de actos de identificación" (Laclau, 1993).

Rechazada la igualación entre la identidad de los sujetos sociales y la posición ocupada por los agentes en la estructura social y, consecuentemente, devaluada la lógica del "descubrimiento o re-conocimiento" como mecanismo de conformación de la subjetividad colectiva -características centrales del modelo marxiano-, el problema en cuestión requiere una 
indagación de las dimensiones intervenientes en la "construcción" de las identidades políticas y en la "desestructuración de las identidades sociales" desde un marco teórico que prescinda de las explicaciones apriorísticas, deterministas y teleológicas. Es en este momento de su desarrollo argumental donde Laclau recurre explícitamente a la trama conceptual del corpus freudo-lacaniano; en primer término, afirma que "[e]l término clave para entender este proceso de construcción es la categoría psicoanalítica de identificación, con su explícita afirmación de la falta en la raíz de toda indentidad: uno necesita identificarse con algo porque existe una originaria e insuperable falta de identidad" (Laclau \& Zac, 1994). A causa de la diferencia entre identidad e identificación es posible formalizar la "presencia de una ausencia como el núcleo traumático de una escisión constitutiva de toda identidad social". La "falta de ser" coloca al sujeto social en posición de demandar a un otro exterior a sí mismo un rasgo indentitario sobre el cual construir su identidad propia mediante el proceso de identificación. Este otro exterior diferente del sujeto es precisamente el lugar de la idea de orden, del espacio "de una cierta regularidad" de significación a la que el sujeto dirige su demanda de significación, buscando encontrar un cierto significante que pueda llenar esa falta de ser que le es constitutiva.

$\mathrm{El}$ orden no adquiere validez porque representa un contenido de significados particulares sino, contrariamente, en razón de que asume una función esencial y correlativa a la falta de ser del sujeto; en otros términos, ofrece la "posibilidad de un orden" que representa un "principio de identificación" para el sujeto. Esta instancia es la contraparte del espacio social caracterizado por práctivas recursivas y "sedimentadas" generadoras de identidades sociales aparentemente consistentes y estables, que parecieran definitivamente incorporadas a una estructura de significación o encadenamiento significante donde se muestran articuladas en una totalidad discursiva de carácter totalizante. 
Cada una de las identidades sociales resultan modificadas a partir de su articulación con otras, formándose así un encadenamiento significante que transforma el significado literal de las identidades parciales al subrogarlas a una serie metonímica formada a través del excedente de sentido inherente a todas ellas. De esta forma, producto de la condensación simbólica a la que han sido sometidas las identidades de los sujetos particulares emerge el sujeto hegemónico. La condición de la lógica equivalencial, sin embargo, no remite a un sujeto trascendental y apriorístico con capacidad de universalización $y$, por ende, posibilitador de la constitución de la serie metonímica. Se deduce, entonces, que el proceso de constitución del sujeto político qua sujeto de la hegemonía debe ser rastreado en el marco de las identidades de los sujetos sociales existentes, eliminado así cualquier tipo de apriorismo metodológico afincado en la idea de un sujeto universal, y, asimismo, postulando, contrariamente, el carácter particular, parcial, contingente e inestable de las identidades de los sujetos sociales. La posición unificada del sujeto politico es, pues, el proceso de articulación de un determinado número de identidades de sujeto parciales sobre la superficie de una cadena significante, anudamiento de sentido que se conforma siguiendo la lógica equivalencial. El proceso de efectuación del sujeto político qua sujeto hegemónico presupone una específica mutación de la identidad de uno de los sujetos particulares, quién realiza una conversión consistente en el desplazamiento de su contenido de significación literal por la representación de un orden comunitario ausente y pleno, asumiendo así la función de universalización, base de la conformación de una relación equivalencial.

El sujeto politico tiene a su cargo la función de articular a las identidades parciales, representadas y nombradas mediante un significante, en una cadena de significación a través del mecanismo de la identificación, concepto formaliza el proceso de ligazón significante producido entre dos instancias de representación identitarias de género diverso, a saber: por un lado, la instancia de representación de los sujetos particulares y, por otro, la 
instancia de representación universal encarnada por aquél sujeto particular devenido sujeto begemónico. Ante las diferentes representaciones significantes particulares, el sujeto político-begemónico es un significante específico que se presenta como el representante de la universalidad, esto es, el representante de un orden comunitario pleno y ausente. La función de esta representanción significante del sujeto político consistirá en ofrecerse como el superficie de inscripción de las "demandas de un orden pleno" para cada una de las diferentes identidades significantes de los sujetos particulares. En este momento del proceso de constitución de las identidades colectivas puede comprenderse, en primer término, a las representaciones identitarias de los sujetos particulares como significantes de la "demanda de completud" -expresada a través de sus reivindicaciones de grupo- y, en segundo término, a la representación universal del sujeto politicobegemónico como el significante de la completud de un orden comunitario que "complementará la falta" de ser de los sujetos particulares. A resultas de este proceso de identificación las identidades de los sujetos particulares se transformarán mediante la incorporación de un rasgo identitario de significación del sujeto hegemónico, al tiempo que cada una de sus identidades será "abrochada" a la cadena significante, organizada en torno a la función universal del sujeto político. El proceso de identificación consiste, pues, en un mecanismo de funcionamiento doble y simultáneo que produce, por un lado, la modificación de las identidades particulares, debido a que éstas incorporan un rasgo significante del sujeto politico y, consecuentemente, son articuladas metonímicamente en una relación equivalencial regida por éste mismo sujeto político, y, por otro, la constitución del sujeto de la hegemonía a causa de que éste sustituye el rasgo significante común de las identidades particulares por la vía de la condensación significante.

En consecuencia, la identidad parcial de los sujetos particulares adopta la forma de una representación significante cuyo significado está escindido entre un sentido literal y un sentido metafórico, dependiendo de las 
relaciones de lucha que cada uno aquellos sujetos establezca con aquel otro que se le presenta como su negación. Al tiempo que el sentido literal de una identidad significante remite al "objetivo concreto de la lucha", el sentido metafórico "significa también oposición al sistema" (Laclau, 1996) o a la estructura social vigente. El sentido literal marca el "carácter diferencial" de su "demanda" en comparación con las luchas de otros sujetos particulares, mientras que el sentido metafórico "establece la equivalencia de todas esas reivindicaciones en su común oposición al sistema" (Laclau, 1996).

Las condiciones de constitución del sujeto hegemónico no son sino las condiciones de efectuación de un sujeto universal de carácter contingente, siendo éste último el resultado de un proceso de mutación mediante el cual el significante identitario de uno de los sujetos particulares abandona su sentido literal para devenir la representación significante del "puro ser de una plenitud comunitaria ausente". De esta manera el "excedente metafórico" de cada una de las identidades particulares es articulado en una serie de equivalencias, conformándose, en consecuencia, una posición de sujeto unificada y universal. Este es el proceso de efectuación del sujeto hegemónico como producción de una representación significante que cobra la forma de un "significante vacío": i.e., un significante que vaciado de contenido puede "representar la identidad puramente equivalencial de un espacio comunitario" ausente. Lo político nombra, entonces, el mecanismo de efectuación del sujeto begemónico como "significante de la falta", proponiéndose así como la "superficie de inscripción y el medio de expresión de todas las luchas emancipatorias, de modo que la cadena de equivalencias que se unifica en torno a este significante tiende a vaciarlo y a desdibujar su conexión con el contenido concreto (el significado) con el que estaba originariamente asociado" (Laclau, 1996), a fin de que éste pueda encarnar la representación pura del orden faltante. 
ABSTRACT: This work reconstructs three theoretical models of linkage beetwen the political subject and the social order, as represented by Hobbes, Marx and Laclau. Hobbes afirms that the political subject, the sovereign, creates the social and juridical order. For Marx, the political subject, the social class, is produced by the social and historical order. Laclau thinks, on his part, that the political subject, the subject of hegemony, is neither maker nor creature of social order, but a process of constitution of a colective and general identity made up from partial and particular identities, that disarray as result of the symbolical desintegration of the social order.

KEYWORDS: political subject, social order, sovereign, social class, hegemony.

\section{Referencias Bibliográficas}

GIDDENS, Anthony. Consecuencias de la modernidad. Madrid, Alianza,1993.

HABERMAS, Jürgen. El discurso filosófico de la modernidad. Buenos Aires, Taurus, 1989. . Teoria y praxis. Buenos Aires, Sur, 1966.

HOBBES, Thomas. Leviathan. Great Britain, University of Cambridge, 1991.

"Del ciudadano". In: Hobbes - Antologia, compilada por Enrique Lynch. España, 1985.

LACAN, Jacques. "La instancia de la letra". In: Lacan - Escritos I. Buenos Aires, Siglo XXI, 1985.

LACLAU, Ernesto, MOUFFE, Chantal. Hegemonia y estrategía socialista. España, Siglo XXI, 1987.

LACLAU, Ernesto, ZAC, Lilian. "Minding the gap: the subject of politics". In: The making of political identities, editado por Ernesto Laclau. United Kingdom, Verso, 1994.

LACLAU, Ernesto. Nuevas reflexiones sobre la revolución de nuestro tiempo. Buenos Aires, Nueva Visión, 1993.

Emancipación y diferencia. Buenos Aires, Ariel, 1996. 
MARX, Karl. "Crítica de la filosofía del derecho de Hegel. Introdución". In: Obras Fundamentales de Marx y Engels, Tomo I. México D.F., Fondo de Cultura Económica,1982a.

"El editorial del número 179 de la Gaceta de Colonia". In: Obras Fundamentales de Marx y Engels, Tomo I. México D.F., Fondo de Cultura Económica,1982b.

"Observaciones sobre la reciente instrucción prusiana acerca de la censura". In: Obras Fundamentales de Marx y Engels, Tomo I. México D.F., Fondo de Cultura Económica,1982c.

"Los debates sobre la libertad de prensa y la publicación de los debates de la Dieta". In: Obras Fundamentales de Marxy Engels, Tomo I. México D.F., Fondo de Cultura Económica,1982d.

"Sobre la cuestión judía". In: Obras Fundamentales de Marx y Engels, Tomo I. México D.F., Fondo de Cultura Económica,1982e.

"Prólogo a la contribución a la crítica de la economía política". In: Introducción General a la crítica de la economía politica. México, Cuadernos de Pasado y Presente $N^{\circ} 1,1982 \mathrm{f}$.

Miseria de la filosofía. Madrid, Ediciones Jucar, 1974.

"Manifest del Kommunischen Partei". In: Der Staat. Dokumente des Staatsdenkens von del Antike bis zur Gegenwart, Zweiter Band. Neske, 1977

MARX, Carlos, ENGELS, Federico. La ideología alemana. Buenos Aires, Pueblos Unidos, 1985.

SCHMITT, Carl. El Leviathan en la teoria del estado de Tomás Hobbes. Buenos Aires, Struhart \& Cía, 1990.

El concepto de lo político. Buenos Aires, Folios, 1984.

TOURAINE, Alain. Crítica de la modernidad. Buenos Aires, Fondo de Cultura Económica, 1993.

TUCK, Richard. "Estudio preliminar al Leviathan de Thomas Hobbes".

In: Leviathan. Great Britain, University of Cambridge, 1991.

WOLIN, Sheldom. Politica y perspectiva. Buenos Aires, Amorrortu, 1989. 